\title{
Collaborative software needs for contract manufacturers
}

\author{
Hans Moonen ${ }^{1,2}$ and Arian Zwegers ${ }^{2}$ \\ ${ }^{1}$ Eindhoven University of Technology, Faculty of Technology and Management, PO Box 513, \\ 5600 MB, Eindhoven, The Netherlands.j.m.moonen@student.tue.nl \\ ${ }^{2}$ Baan, Baron van Nagellstraat 89, 3771 LK, Barneveld, The Netherlands. \\ hmoonen@baan.com,azwegers@baan.com
}

\begin{abstract}
The supply chains in the Electronics industry have gone through some major changes over the last decades. Today's Electronics landscape is highly competitive, with short product lifecycles, and unpredictable demands. Many specialized players have appeared in the industry. There is a growing need for collaboration between the different parties in this industry, which can be supported by software solutions. This paper identifies what collaborative software solutions Electronics Manufacturing Services (EMS) companies are seeking, how these solutions depend upon the chosen value discipline, and how their needs are prioritized. A framework for collaboration for Electronics Manufacturing Services providers combines collaborative functions with value discipline thinking. Four areas arise as highly interesting, namely collaborative design for optimal products, collaborative fulfilment planning, collaborative customer service, and collaborative design for innovative products. Different value disciplines lead to different collaborative solutions.
\end{abstract}

\section{Keywords}

Collaboration; c-Commerce; Value Disciplines; Supply Chain Management; Contract Manufacturing; Electronics Industry.

\section{INTRODUCTION}

Globalization, short product lifecycles, short time-to-market, more customerspecific products and decreasing prices are some of the issues the Electronics industry faces today. Over the past years, the Original Equipment Manufacturers (OEMs) in this industry have begun to outsource many more of their processes, and so the Electronics supply chain outlook has changed. The largest part of manufacturing outsourcing is transferred from these OEMs to the Electronics Manufacturing Service providers (EMS), also called Contract Electronics Manufacturers (CEMs). The market for EMS companies is expected to show a large growth over the coming years.

As a result, the supply chain in Electronics is far more complex nowadays, with a lot of specialized players in the chain. There is a growth in the number of inter- 
dependencies between the different players. The supply chain is becoming less linear than it was before, and is evolving more and more into a network of interdependent companies.

One of the biggest risks this new structure of the Electronics industry brings is the possibility of miscommunication and the inefficiencies caused by the gap between those who design, market and sell the product, and those who manufacture it. To overcome this, to face the (end -) customers as one enterprise, and also to improve speed, visibility and trust in the supply chain, the different companies in the chain need to synchronize their activities and processes, and really start collaborating with each other. EMS companies, for example, can collaborate with their (most strategic) supply chain partners in business processes, such as design, forecasting, sales, and customer support.

The objective of this paper is to identify what collaborative software solutions EMS companies are seeking, how these solutions depend upon the chosen value discipline, and how their needs are prioritized. Each company needs to choose one of three identified value disciplines, namely customer intimacy, product leadership, or operational excellence. The collaborative software needs of EMS companies differ depending on the value discipline chosen. EMS companies with different value disciplines prioritize their needs for collaborative processes differently.

Knowledge from (academic) literature was combined with knowledge from domain experts to get a better understanding of the market for collaborative software solutions in the Electronics industry, and to provide recommendations for future software directions. Furthermore, input from EMS companies was used.

The next section identifies the key business issues EMS companies are facing. A supply chain management model is presented later, and the three different value disciplines are introduced in the subsequent section, including the input from previous sections into different concepts for collaborative software solutions for different value disciplines. A discussion concludes this paper.

\section{BUSINESS ISSUES}

\section{Historical changes in the Electronics industry's structure}

Before the 1980s, the supply chain in the Electronics industry could be characterized, in general, as shown in a simplified manner in the upper part of Figure 1. Original Equipment Manufacturers (OEMs) got their material from material suppliers and manufactured that into products they delivered to their customers. Sometimes, they outsourced some of the production to companies referred to as Contract Electronics Manufacturers (CEMs). OEMs turned to outsourcing mainly to provide supplemental manufacturing capacity during periods of high demand (Carbone, 2000; Tomasch, 2001). The relationship between OEMs and their CEMs was thin. The work was contracted on a consignment basis, and it was easy for OEMs to move work from one CEM to another.

Changing production technology in the 1980s and early 1990s was the major deciding factor that resulted in a shift in the supply chain operations structure. 
OEMs started to use CEMs more and more as their primary production facilities (see second part of Figure 1). It did not make sense for OEMs to invest in all the expensive equipment themselves. CEMs could achieve better equipment utilization, because they could combine work from multiple OEMs - the manufacturing processes are easily standardized, but companies and supply chains are searching for best business practices (Maia Goldstein, 1999). Therefore the role of CEMs was changing from 'additional capacity' for the OEMs, to providing (cheap) technical manufacturing expertise that OEMs did not have.

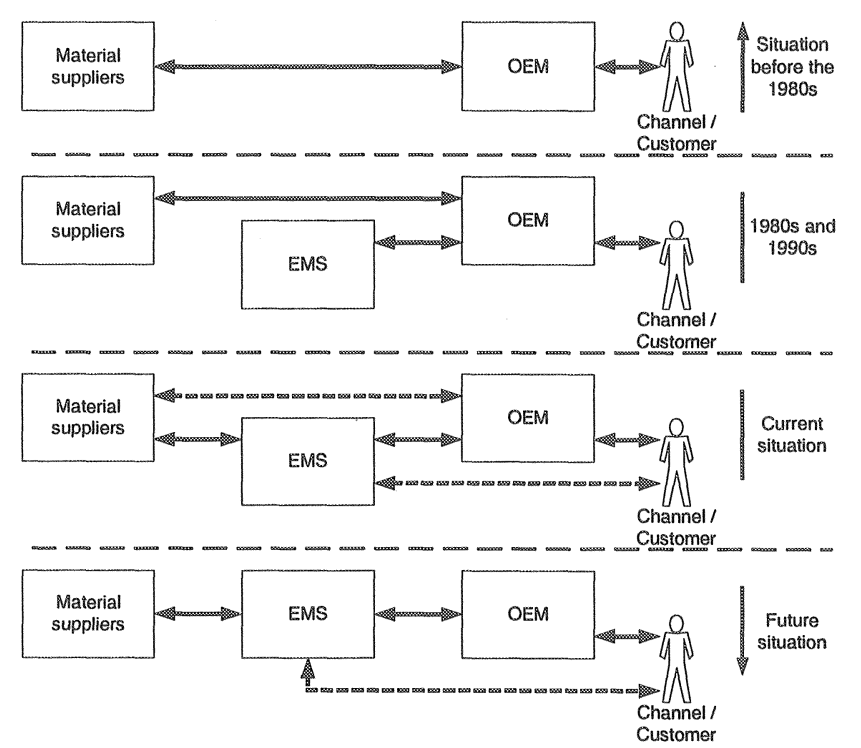

Figure 1 - Position of EMS in the Electronics Supply Chain

In the 1990s, large contract manufacturers began to differentiate themselves as Electronics Manufacturing Service providers (EMS). They started to function more as the operating departments of OEMs, offering superior Total Cost of Ownership (TCO). OEM companies in the Electronics industry have been shrinking non-core competencies and focusing intensely on their core competencies (Anon 2000), which may or may not include actually building products. EMS companies offer engineering, design, testing, assembly, order-processing, distribution, and after market support (such as repair services). See third part of Figure 1, the dashed lines indicate optional relationships.

Functions that were once concentrated in one or two players in the value chain, such as order management and fulfilment, are now performed by multiple companies acting as though they are one. The supply chain operates as if it is one company (Anon 2000).

The bottom part of Figure 1 indicates that the role of EMS companies in a supply network is likely to grow in importance. OEMs will outsource more and more processes, and the EMS companies take up the role of network orchestration (Bovett \& Martha 2000; Lowe \& Markham 2001). 


\section{Supply chain typology}

The supply chain typology of the Electronics industry shows a large similarity with the Fashion industry typology (Fischer 1997; Sharman 2001). Typical aspects are its high value density, short life cycles, innovative products, unpredictable demands, obsolescence rates, etc. A responsive supply chain is needed, and so control and optimization centre around four themes: transition management, forecasting, inventory management, and lead-time reduction.

The transition management theme is important, as it is demonstrated by the fact that the contribution margin is high at new product launch. It is better to ensure supply in such cases, for example by a 'surplus' in capacity. Furthermore product manufacturability is important, since it can be influenced in the design phase. Reducing the design lead-time can be beneficial as well.

Long supplier lead-times and a limited flexibility underline the importance of forecasting. The range of end products is large, resulting in unreliable forecasting, but there is high component modularity. This results in forecasts at product family level for production and components. Sharing information along the chain is seen as critical, especially feedback of end consumption data.

The high value density of the products is not the only aspect that asks for inventory management. The difficulty to forecast at item and outlet level for the end products also demands inventory management and rapid replenishment. The high cost of key components and materials require maximized component commonality and well-managed component inventory levels.

High obsolescence rates, a short time of sale-ability, and a short model half life time request not only optimal product transitions but also lead time reductions, or a reduced time-to-market. Furthermore, customers become more exigent every day and require shorter lead times. This relates to faster product development processes (e.g. from idea to product), and shorter fulfilment times (e.g. from order to use). Combined with the large range of end products, manufacturing postponement does seem to be a solution, which pleads for a move of the customer order decoupling point from a make-to-stock environment towards a make-to-order environment.

Lost sales and obsolescence (Callioni and Billington, 2001; Gutgeld and Beyer, 1995) are interdependent. It would be easy to achieve zero lost sales, for example by over-stocking everything up to the hilt, but the obsolescence costs of this approach would be formidable. In the early part of the life cycle, on hand inventory is critical to achieve zero lost sales. However, at the end of a product life cycle a surplus of obsolete items can become very costly. The challenge is to find the optimal trade-off between the two factors, which will vary from situation to situation. Measuring the 'immeasurable' - namely obsolescence costs and lost margins on missed sales - is an important instrument in managing this trade-off process, since it provides the company with valuable insight in the market situation.

This information leads to the conclusion that the following issues are very important to control in the Electronics industry:

* Shorter design times

w Design for manufacturability (DFM)

- Common components (combined with good inventory control)

₫ Reduced lead times 
- Responsive and rapid fulfilment

a Make-to-order environment combined with production postponement

- Manage the trade of between lost sales and obsolescence

- Intelligent sharing of data in the supply chain

\section{SCM AND COLLABORATION}

\section{Definition of supply chain management}

Despite the popularity of the term Supply Chain Management (SCM), both in academia and industry, considerable confusion as to its meanings remains. Some define SCM in operational terms involving the flow of materials and products, some see it as a management philosophy, and some view it in terms of a management process. This paper uses the following definition:

"Supply chain management is defined as the systemic, strategic coordination of the traditional business functions within a particular company and across businesses within the supply chain, for the purposes of improving the long-term performance of the individual companies and the supply chain as a whole." (Mentzer et al., 2001)

SCM in the market for enterprise software means something different in academia. In the enterprise software market, vendors have positioned their Advanced Planning \& Scheduling systems (APS) as SCM tools. In practice, however, these tools do only optimize and coordinate within the four-walls of an organization, and not along the whole supply chain. Enterprise software vendors (such as Baan, SAP, i2, etc.) and the industry analysts (such as Gartner, AMR Research, Forrester, etc.) speak about collaboration in regards to software solutions for managing relationships in the supply chain. Throughout this paper the following definition will be used:

"Collaboration is the process of working together toward a common purpose or goal in which the participants are committed and interdependent, with individual and collective accountability for the results of the collaboration, and each of the participants shares a common benefit." (Light et al., 2001)

It is clear that these definitions of collaboration and supply chain management have much in common. Both definitions are all about working together, to derive benefits from this, and to improve supply chain efficiencies.

\section{Supply chain model}

As there are many definitions for supply chain management and collaboration, there are also many different supply chain models. Figure 2 shows the one used in this paper. It is based upon (Mentzer et al., 2001), but with a slight adjustment. A large difference with traditional supply chain models - which look at each of the 
various companies - is that this model takes the supply chain, of different partners, as the basis.

In the centre of the model, nine functions are placed which need to be fulfilled by the supply chain as a whole, like $R \& D$, forecasting and sales. Please note that design is a part of the research \& development function in this model, and that the term 'logistics' includes both distribution and inventory management.

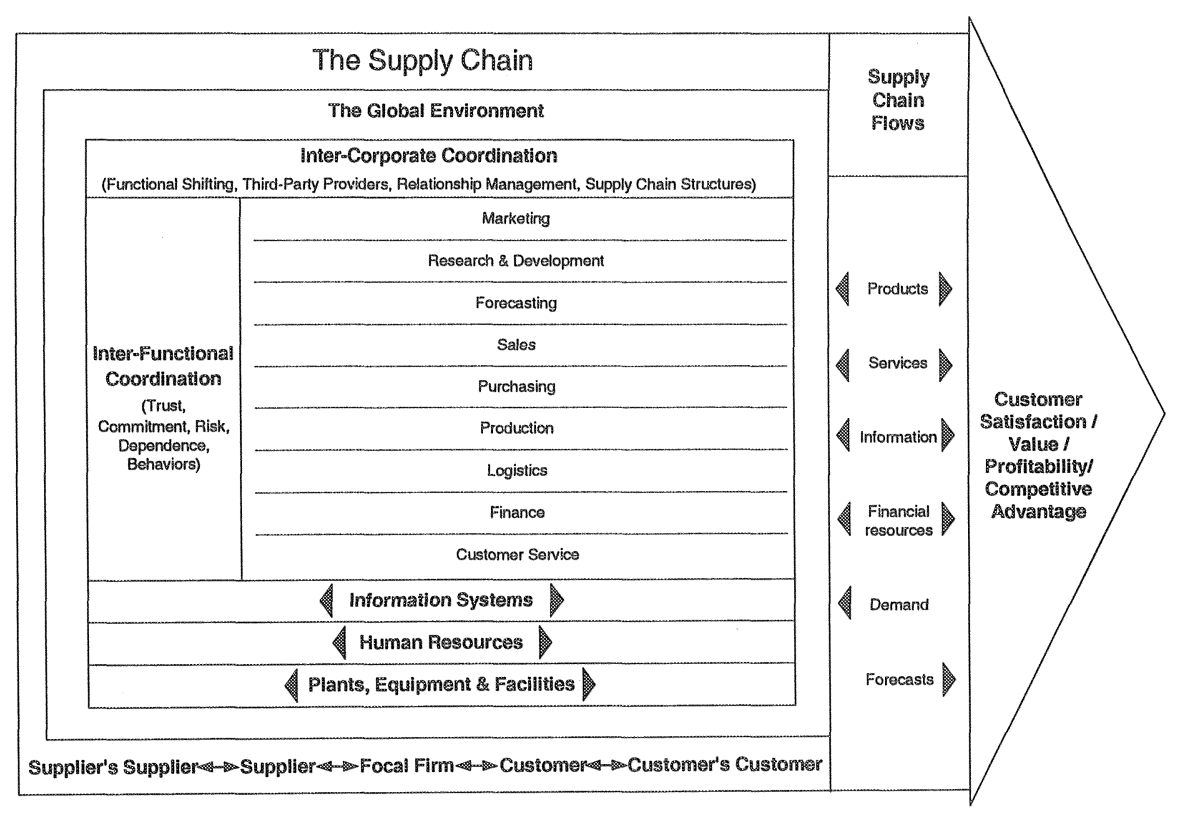

Figure 2-Model of supply chain management, based on (Mentzer et al., 2001)

Part of this supply chain model is also an overview of the enablers for interfunctional coordination, such as trust, commitment, and behaviours. The supply chain flows (such as products, services, financial resources, and information) are there, as are the benefits the supply chain brings. In the end, it is all about customer satisfaction, value creation, profitability, and competitive advantage over other supply chains.

Information systems, human resources and plants, equipment and facilities are positioned in a separate part of the model. These aspects support the operation of the different functions, by the individual companies and by the supply chain as a whole.

\section{VALUE DISCIPLINES}

\section{Competitive differentiation}

According to some recent literature (Hagel \& Singer, 1999; Lakenan et al., 2001; Porter 2001; Treacy \& Wiersema 1993; Treacy \& Wiersema 1995), there are three disciplines where today's companies can excel and gain competitive 
differentiation. The three competitive differentiators are customer intimacy, product leadership, and operational excellence. Bundling all these three value disciplines into a single company inevitably forces management to compromise the performance of each process in ways that no amount of reengineering can overcome, simply because the economics of these processes conflict. As a result of this, it seems to be really difficult to combine all areas into one single company.

A company that focuses on customer intimacy offers its customers as many products and services as possible, which requires an intensely service-oriented culture. It stands for segmenting and targeting markets precisely and then tailoring offerings to match exactly the demand of those niches. For a company where product leadership is the key competitive differentiator, speed, not scope, drives the economics. Innovation is rewarded and administration is minimized. The company offers its customers leading-edge products and services that consistently enhance the customer's use or application of the product or service, thereby making rival's goods obsolete. In case a company wants to excel in operational excellence, the company wants to make use of its operational facilities as optimally as possible, based on the high-fixed costs it faces, and on its capital-intensive facilities. The focus is on delivering their customers reliable products or services with minimal difficulty or inconvenience. These companies do the same as their competitors, but do them better (and are cheaper). Companies that have chosen one of the other differentiation strategies just try to do things differently from competitors, so delivering a unique type of value to customers. Figure 3 shows some examples of three different companies, in the same industry, mapped against the three different value disciplines.
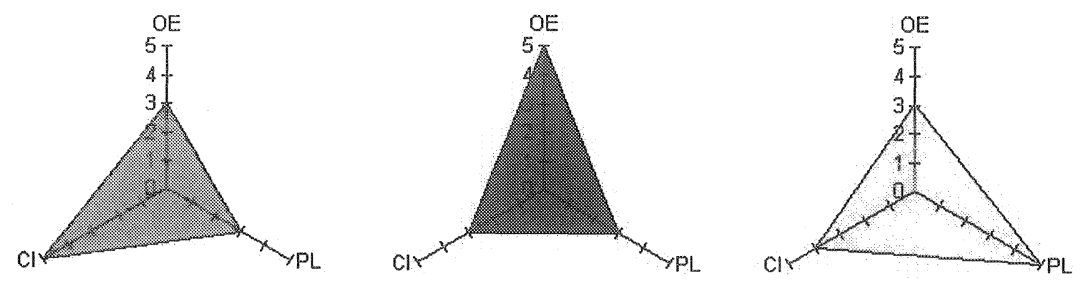

Figure 3-Examples of companies mapped against the three value disciplines.

\section{Focus is the key}

Focus on one of the three value disciplines is the basis for competitive advantage. This can be explained by both the concept called 'the zone of indifference' as well as with the growing influence of modern ICT in current industries.

'The zone of indifference' theory (Knie-Andersen, 2001) shows that there is an indifferent zone between the upper level of the degree of satisfaction "dissatisfied" and the lower level of "very satisfied". Moving positions within the zone of indifference does not make too much sense, because the customer does not recognize the added value. The customer first recognizes the extra value when a 
company moves into the area "very satisfied". It seems logical that the three aspects related to the different value disciplines (i.e. best costs, best product, and best total solution) all have their own zone of indifference. Customers only recognize the real market leaders, related to best cost, best product, or best total solution, if they excel outside this zone of indifference. As a result, concentrating the focus on one of the disciplines, instead of taking baby steps in all the disciplines, might prove more sensible since it moves a company outside the zone of indifference, and thus provides more added value to customers. Note that industry standards are inclined to rise every year, so companies need to keep on improving on all fronts.

The introduction and implementation of new information technologies brings a lot of improvements and advantages (like lowering the interaction costs), but on the other hand it makes it more difficult for companies to capture the benefits it creates, while best practices are easier to copy (Porter, 2001). Having a middle-of-the-road strategy, where a company tries to become a champion in two or even three of the value disciplines, results in easy to copy best practices. A company that focuses on only one value discipline might have the chance to build true value in its information systems, which may not be that easy to copy. Once again, focus is the key word.

Although focus on one value discipline is the key to success, this does not mean that the other disciplines can be ignored. A market leader with a strong focus on one value discipline needs to meet at least the industry standards in the other disciplines. The zone of indifference theory shows that the industry standard can be relatively easily met, since it is located between large borders, but it is much harder to move beyond the industry standard.

\section{Value disciplines in the Electronics industry}

Over the last two decades OEMs started to shift their focus more and more towards customer intimacy and/or product leadership, and started looking for opportunities to outsource their non-core processes. EMS providers were (and are) the logical choice for outsourcing the no-longer-core manufacturing processes, with their strong value discipline focus on operational excellence. Cost and reliability are the main reasons for outsourcing from OEMs to EMS companies.

The consolidation in the number of EMS companies that has been going on recently, combined with their growing size and rising global presence, only strengthens their superiority in an operational excellence perspective. In these companies, everything is focused on efficiency and utilization.

History is not the only explanation for the division of different roles in the supply chain, since it is also caused by the supply chain structure itself. It might be stated that the value discipline is more or less dictated by the position in the supply chain network. For example, an EMS company generally does not have to face endcustomers, therefore a customer intimacy focus is not the most logical one.

\section{The value disciplines for an EMS company}

Although from a complete supply chain perspective the role of an EMS was, is and will remain to be that of a specialist in operational excellence, an EMS does not need to focus on operational excellence only. To differentiate itself from other EMS 
companies, and to enforce its competitive position, an EMS company can choose to excel in one of the three value disciplines, thereby meeting the high standard for operational excellence directed by the industry structure. By choosing a different strategy than competitors do, an EMS can become more appealing to its OEM customers.

An EMS company can differentiate itself from other EMS's by an even stronger focus on operational excellence than competition, or by focusing its efforts on customer intimacy or product leadership. A focus on customer intimacy agrees with other EMS companies that create a relationship with the end customer. Sales, service, and fulfilment are handled (or coordinated) through the EMS, and products do not touch the OEM anymore. The setup of so-called 'new product introduction centres' and (joint) R\&D programs are perfect examples of EMS companies that focus more on product leadership.

It is important to realize that cost advantages are less perishable than customer binding or a product market leadership (Porter, 2001). Knowing this, an EMS company can be attracted to shift its focus more towards customer intimacy or product leadership, while remaining operational excellent at industry standards level. By focusing on these activities, it does not only strengthen its competitive position, but it also has a way to achieve higher profit margins.

In general, an EMS consists of different locations and plants. As some of the examples from literature clearly illustrate (McKone \& Tumolo, 2002), it may be very well possible that one plant is better suited for customer intimacy and another better for purely operational excellence. A third plant can then excel in product leadership. This can especially happen to the larger EMS companies, which are facing such diverse situations. The focus for a value discipline may differ per plant, (OEM) customer, or even per product, which relies upon the requests from the customer.

A product can request a product leadership strategy at product introduction, the first phase of its life cycle, but it might request an operational excellence strategy when it matures. This can result in shifting the production from one plant to another, or even from one EMS to another EMS (McKone \& Tumolo, 2002).

\section{COLLABORATIVE PROCESSES DEPENDENT ON THE VALUE DISCIPLINE}

\section{Collaborative software solutions}

Becoming aware of the need for collaboration and advanced supply chain management in the Electronics industry and the impact value discipline thinking has, it becomes clear that a new approach is needed. Traditional thinking is very much a four-wall focus, and differences between different value disciplines are hardly ever made.

The matrix as shown in Figure 4 functioned as the basis for the next step in the research. It helps to get insight into the real collaborative needs of EMS companies in the Electronics industry, depending on their chosen value discipline. One axis shows the value disciplines, and the other axis the collaborative functions - adopted 
from the SCM model in Figure 2. Note that the matrix shown here is not filled with information. The matrix used in the analysis was filled with information. This matrix only shows some 'hotspots' for collaboration, which are discussed in the remainder of this paper.

\begin{tabular}{|c|c|c|c|}
\cline { 2 - 4 } \multicolumn{1}{c|}{} & $\begin{array}{c}\text { Operational } \\
\text { excellence }\end{array}$ & $\begin{array}{c}\text { Customer } \\
\text { intimacy }\end{array}$ & $\begin{array}{c}\text { Product } \\
\text { leadership }\end{array}$ \\
\hline Marketing & 1 & & \\
\hline R\&D & & & \\
\hline Forecasting & & & \\
\hline Sales & & & \\
\hline Purchasing & & & \\
\hline Production & & & \\
\hline Logistics & & & \\
\hline Finance & & & \\
\hline Service & & & \\
\hline
\end{tabular}

Figure 4 - Collaborative functional areas and the three value disciplines

Clearly, EMS providers that adopt a customer intimacy strategy focus on other aspects than an EMS provider that has chosen to excel in purely operational excellence. This translates into their collaborative processes also. There are not only differences between the priorities for different collaborative processes, but there can also be a difference between the processes in relation to the chosen strategy.

Figure 5, for example, shows the collaborative design process for EMS companies, with corresponding driving forces. Collaborative design turns out to be especially interesting for companies with an operational excellence or product leadership strategy. Nevertheless, the driving forces for collaborative design for those two solutions are quite different. An EMS, which starts to collaborate upon design, has as its main drivers design-for-manufacturability and design-fortestability. Under a product leadership strategy, time-to-market combined with a focus on new product introduction (NPI), and handling design complexity turn out to be very important. Consequently, the software solutions that support these processes may differ as well. 


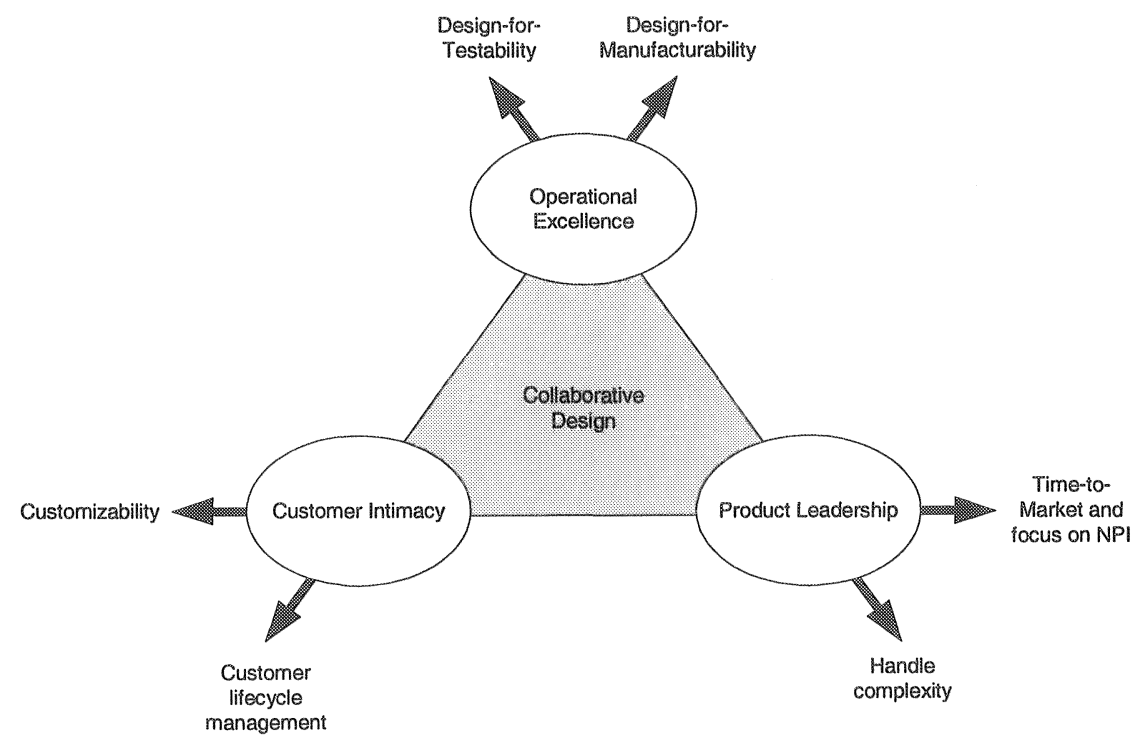

Figure 5-The objectives of a collaborative process differ by value discipline

Analysis shows that the matrix in Figure 4 provides four hotspots where collaboration can make a difference for EMS companies in the Electronics industry. Expert input, industry knowledge and literature study pointed to these hotspots where best practices in collaboration for EMS companies can be achieved. These hotspots are:

- Collaborative design for optimal production

- Collaborative order fulfilment planning

" Collaborative customer service

- Collaborative design for innovative products

\section{Collaborative design for optimal production}

Collaborative design, the process of designing new products together with suppliers and/or customers, can be very valuable for companies that operate with an operational excellence strategy. The reasons are diverse, but in generally caused by the gap between those who design (e.g. the OEM) and those who produce (e.g. the EMS). Tighter coupling of design and manufacturing can result in cost savings and more efficient production techniques. Note that about $75 \%$ of the costs of a product are linked to the original design (Cahn \& Swanton, 2001; McKone and Tumolo, 2002).

Integrating feedback from the EMS factory floor and making use of the supply chain and operational knowledge from the EMS can bring large improvements in the design of new products. It ensures that the manufacturing and supply chain experiences of the EMS provider are reflected in the product.

Some examples are: 
- Direct feedback from the factory floor can result in designs that are easier to manufacture and/or easier to test. This is described as Design-forManufacturability (DFM) and Design-for-Testing (DFT).

- Integrating knowledge around the right materials to use can be beneficial as well. Knowing which parts will become obsolete soon, or which parts cannot be combined with other parts, or under which conditions alternatives might be used can be of good help.

- Economies of scale - for example by recommending a part that is also used for another OEM customer - might benefit the design, simply because it influences the final product's costs.

This is evident for new product designs, but it also applies to design enhancements during the lifecycle of the product. Nevertheless, the processes do differ, and part of the design process can be the design of the physical supply chain.

EMS companies realize the benefits collaborative design can bring and they are beginning to experiment in this field. Some of these companies are driven by the simple reason that they had to take over production facilities from OEMs that included engineering divisions. Others just realized the benefits as described above and set up joint processes with their supply chain partners.

\section{Collaborative order fulfilment planning}

Especially for companies with an operational excellence or customer intimacy focus, sales and purchasing become very important. In case a company masters these aspects, it is better suited to operate at low costs, or match the exact customer requirements. When starting to think in a collaborative manner, sales and purchasing become even closer related than they already used to be. A sales order triggers a purchase process and companies are no longer seeking to optimize only their own company situation. Optimization of the whole supply chain network might be a better choice. All this is part of collaborative order fulfilment planning. Examples from other industries (Margretta 1998) show that it may be well possible that the Electronics industry's landscape might look slightly different a few years from now. An order does not follow a predefined route anymore, neither does it follow the route the last order did, but it does get planned and optimized at the moment it is captured. This brings large benefits when optimization happens based upon capacity, costs, profits, speed, and other constraints.

Collaborative order fulfilment planning helps to take more optimal production decisions, and so it realizes cost savings. The decisions taken are based upon the capacities, utilization, and costs in the complete network. Optimization in the fulfilment planning process is done for the complete supply chain network instead of local optimization of the individual parts of the chain. An integral process that can integrate the manufacturing and distribution issues from the different partners is needed, since local optimization is not always what benefits the supply chain most. Overall network optimization is key, and it might be possible that some of the chain partners do not reach local optimization. This process therefore involves suppliers, and sometimes even the suppliers' suppliers, and it includes the different plants of 
the EMS itself. On the other side of the network, the OEM, the channel partners, and the 3PL providers might be integrated as well.

The process starts with a request from the customer (i.e. the OEM or the endcustomer). Based upon this request, the collaborative order fulfilment planning solution checks the different ways the product can be built and routed. The same end-product can sometimes be assembled via different bill-of-materials (BOMs). Making the right decisions here, in respect to costs and availability (i.e. inventory vs. goods to procure), can result in huge financial savings. Furthermore, it can be beneficial to plan the fulfilment process network-wide. Choices for the different suppliers, delivery terms, and production locations can be based upon issues related to capacity, related costs, utilization rates, distances, time related issues, etcetera. The main questions to answer and optimize are what, where, how and when to produce, and how and when to deliver.

Although at first glance collaborative order fulfilment planning may look like a simple extension to the old order promising processes, where Available-to-Promise (ATP) and Capable-to-Promise (CTP) calculations delivered insight in production and delivery capabilities, it goes way beyond that, and perhaps even beyond Profitable-to-Promise (PTP). The focus is network-wide, which means crossenterprise, instead of an enterprise or even plant-centric view. Furthermore, it includes distribution issues. Last, but not least, it also takes issues related to multiple children BOMs into account. Altogether, the planning will be much better suited to boost the overall network performance capabilities. Next to that, this process can be used for another optimization-round, in case the situation changed and plans need to be updated. Moonen (2002) gives an extended description of a collaborative order promising process.

Automatic optimization of fulfilment decisions and the network-wide CTP capabilities support production postponement and a shift towards make-to-order environments (Anon, 2000). The customer plays an important role in the whole process and can have part in an (automatic) negotiation process.

\section{Collaborative customer support}

Customer support was traditionally an area for the company that was responsible for sales to the final customer (e.g. the OEM), and it will most likely remain one of the core competences of most of the OEMs, especially since it is one of the contact points with the customer (Bovett and Martha, 2000). Nevertheless, that does not hinder a larger role for EMS's in the process of customer service. Especially, considering the fact that an EMS becomes more and more the owner of product knowledge, it is in a logical position to give support. EMS companies with their focus on customer intimacy might consider moving into the area of collaborative customer support.

For each product, an EMS can store all related information. Information such as bill-of-material (BOM) used, production dates, suppliers used, etcetera, might play a vital role in the support process. Specific questions can be rerouted to the respective experts, and problems with the products can be discovered earlier. Feedback from the market - about failures, problems, etc. - gets back to the source sooner and may result in better products. 
Note, that software becomes increasingly part of products. It is a product feature that might result in product upgrades later in the products life, and it may solve problems that can occur. Especially for this kind of software (mostly referred to as embedded software) the knowledge from the source benefits the quality and velocity of a solution.

\section{Collaborative design for innovative products}

Collaborative design might not only be valuable for companies with an operational excellence strategy focus; for companies that differentiate themselves as product leaders, it is absolutely necessary. Product leaders need to operate with state-of-the-art technology, with time-to-market pressures, and continuing new product introductions (NPI).

Time-to-market pressures require product leaders to develop their products as fast as possible to get it to market quickly (Anon, 2000; Porter, 2001). Different specialists from different supply chain partners across locations work together on new products, and manufacturing and service organizations play a role as well. Furthermore, they have to focus on NPIs, and to prepare for the roll-out phase. Companies that deliver state-of-the-art technology are always facing the challenge of complexity. Knowledge sharing gets very important since this is an instrument to overcome complexity.

For such companies, R\&D and design are never-ending stories. It is the fundamental key to business, which is not only displayed in collaborative product designs, but also in state-of-the-art joint research projects where OEMs, EMS companies, and perhaps even parts suppliers are involved.

\section{DISCUSSION}

This paper takes a systematic approach to find opportunities for collaboration in the Electronics industry, from the standpoint of an EMS provider. The Electronics industry, with its different stakeholders and business issues are introduced. Supply chain management and collaboration between supply chain partners within this industry are of great importance. When combining this knowledge with modern insights around business strategies - i.e. value disciplines - it becomes clear that there is not one single standard method of reasoning. The need for collaborative software solutions depends upon the chosen focus and strategy. A research matrix shows four areas where collaboration is of great importance.

This paper can function as a starting point for more detailed research in this area. It can be of great value, for different reasons, to companies in the Electronics industry (i.e. EMS companies), to enterprise software vendors, and to the academic community:

- Companies in the Electronics industry (EMS providers, but also OEMs and suppliers) can use the framework to Figure out how to design their collaboration strategy, based on their specific business issues and their competitive strategy. 
a Enterprise software vendors can use the framework to develop and position software solutions for collaboration, as generically as possible, to cover the diverse market where EMS companies operate. This systematic approach will create valuable input for their solution roadmaps.

- It provides the academic community with a better insight in the way these kind of companies function in their supply chains, and thus a better starting point for further research.

Further research may be initiated in a number of themes. The hypothesis that the Electronics industry structure will change over the coming years needs to be validated. The application of the concepts in this paper to other industries, such as the automotive, aerospace $\&$ defence, and heavy equipment industries, needs to be studied. Finally, network orchestration is sometimes mentioned as a fourth value discipline (Bovett and Martha, 2000; Lowe and Markham, 2001). Research is needed to determine whether it is indeed a fourth discipline, and if so, how network orchestration impacts supply chains and leads to new or improved software solutions.

\section{REFERENCES}

[1] Anon. 'Beyond ERP - Collaboration and value networks'; Benchmarking Partners and IBM whitepaper; 2000

[2] Bovett, David; Martha, Joseph; 'Value Nets - Breaking the supply chain to unlock hidden profits'; John Wiley \& Sons, Inc.; Mercer Management Consulting; 2000

[3] Cahn, David M.; Swanton, Bill; 'Collaborative manufacturing execution (CME) powers outsourced high-tech manufacturing'; AMR Research publication, The report on manufacturing e-business; March 2001

[4] Callioni, Gianpaolo; Billington, Corey; 'Effective Collaboration'; OR/MS Today; October 2001

[5] Carbone, James; 'What buyers look for'; Purchasing; March 23, 2000

[6] Fisher, Marshall L.; ,What is the right supply chain for your product?'; Harvard Business Review; March, 1997

[7] Gutgeld, Yoram; Beyer, Damon; 'Are you going out of fashion?'; The McKinsey Quarterly; Number 3, 1995

[8] Hagel, John; Singer, Marc; 'Unbundling the corporation'; Harvard Business Review; March 1999

[9] Knie-Andersen, Michael; 'The relationship between customer satisfaction, customer loyalty, and customer profitability'; Working paper 2001 - 21, University of Aarhus; Denmark; 2001

[10] Lakenan, Bill; Boyd, Darren; Frey, Ed; 'Why Cisco fell'; strategy + business; issue 24; Third Quarter 2001

[11] Light, M.; Bell, M.; Halpern, M.; 'What is collaboration? Virtual team success factors'; Gartner Group, COM - 14 - 4302; December 21, 2001

[12] Lowe, Paul G.; Markham, William J.; 'Perspectives on Operations Excellence'; Supply Chain Management Review; November/December 2001

[13] Maia Goldstein, Barbara L.; "A standard-based approach to integrating information across the Electronics manufacturing supply network'; United States Department of Commerce; ECWC8 Tokyo; September 9, 1999 
[14] Margretta, Joan; 'Fast, Global, and Entrepreneurial: Supply Chain Management, HongKong style'; Harvard Business Review; September, 1998

[15] McKone, Kathleen E.; Tumolo, Paul; 'Redefining contract manufacturing'; Supply Chain Management Review; January/February 2002

[16] Mentzer, John T.; DeWitt, William; Keebler, James S.; Min, Soonhong; Nix, Nancy W.; Smith, Carlo D.; Zacharia Zach G.; 'Defining Supply Chain Management'; Journal of Business Logistics; Volume 22, No. 2, 2001

[17] Moonen, Hans M.; 'Collaborative software for EMS companies'; MSc. thesis Eindhoven University of Technology; 2002 (to be published)

[18] Porter, Michael E.; 'Strategy and the Internet'; Harvard Business Review; March 2001

[19] Sharman, Graham J.; 'SC factors, typologies, and improvement levers'; Eindhoven University of Technology slideset used in SLIM (1t080) course; September 2001

[20] Tomasch, Reiko; 'EMS evolution continues'; Gartner Group, Research Brief; August 29,2001

[21] Treacy, Michael; Wiersema, Fred; 'Customer intimacy and other value disciplines'; Harvard Business Review; January, 1993

[22] Treacy, Michael; Wiersema, Fred; 'The discipline of Market Leaders'; Addison-Wesley Publishing; 1995 